\title{
Evaluation of ER, PgR, HER-2 and Ki-67 as predictors of response to neoadjuvant anthracycline chemotherapy for operable breast
}

\section{cancer}

\author{
RJ Burcombe', A Makris*,', PI Richman', FM Daley², S Noble², M Pittam³ , D Wright ${ }^{3}$, SA Allen ${ }^{3}$, J Dove ${ }^{3}$ and \\ GD Wilson ${ }^{2}$
}

'Academic Oncology Unit, Mount Vernon Hospital, Rickmansworth Road, Northwood, Middlesex HA6 2RN, UK; '2Gray Cancer Institute, Mount Vernon Hospital, Rickmansworth Road, Northwood, Middlesex HA6 2RN, UK; ${ }^{3}$ Luton \& Dunstable Hospital, Lewsey Road, Luton, Bedfordshire LU4 ODZ, UK

Primary systemic therapy (PST) for operable breast cancer enables the identification of in vivo biological markers that predict response to treatment. A total of I I 8 patients with T2-4 NO- I MO primary breast cancer received six cycles of anthracycline-based PST. Clinical and radiological response was assessed before and after treatment using UICC criteria. A grading system to score pathological response was devised. Diagnostic biopsies and postchemotherapy surgical specimens were stained for oestrogen (ER) and progesterone (PgR) receptor, HER-2 and cell proliferation (Ki-67). Clinical, radiological and pathological response rates were 78, 72 and 38\%, respectively. There was a strong correlation between ER and PgR staining $(P<0.0001)$. Higher Ki-67 proliferation indices were associated with PgR- tumours (median 28.3\%, PgR + 22.9\%; $P=0.042$ ). There was no relationship between HER-2 and other biological markers. No single pretreatment or postchemotherapy biological parameter predicted response by any modality of assessment. In all, 10 tumours changed hormone receptor classification after chemotherapy (three ER, seven PgR); HER-2 staining changed in nine cases. Median Ki-67 index was $24.9 \%$ before and 18.1\% after treatment $(P=0.02)$; the median reduction in Ki-67 index after treatment was $21.2 \%$. Tumours displaying $>75 \%$ reduction in Ki-67 after chemotherapy were more likely to achieve a pathological response $(77.8$ vs $26.7 \%, P=0.004)$.

British Journal of Cancer (2005) 92, |47-155. doi:10.1038/sj.bjc.6602256 www.bjcancer.com

Published online 21 December 2004

(c) 2005 Cancer Research UK

Keywords: breast cancer; chemotherapy response; ER; HER-2/neu; Ki-67; neoadjuvant chemotherapy; PgR

Neoadjuvant chemotherapy or primary systemic therapy (PST) for operable breast cancer provides an opportunity to evaluate biological markers that may predict response to treatment. The identification of tumour parameters that accurately predict response to treatment would be of value in optimising PST so that nonresponders could be offered alternative and more effective therapies.

Biological markers used in routine clinical practice were selected for the purposes of this analysis. Oestrogen receptor (ER) and progesterone receptor (PgR) status are widely used to select patients for adjuvant hormonal therapy (Allred et al, 1998; EBCTCG, 1998; Harvey et al, 1999) and may predict response to cytotoxic chemotherapy in metastatic disease (Kiang et al, 1978; Lippman et al, 1978; Lippman and Allegra, 1980), but their role in predicting response to primary chemotherapy remains controversial. Human epidermal growth factor (HER-2) overexpression has been associated with poor overall prognosis, shorter relapse-free and overall survival (Slamon et al, 1987), sensitivity to optimal dose anthracycline chemotherapy (Thor et al, 1998) and resistance

*Correspondence: Dr A Makris; E-mail: andreas.makris@whht.nhs.uk Received 21 May 2004; revised 14 October 2004; accepted I8 October 2004; published online 21 December 2004 to adjuvant anthracycline chemotherapy and tamoxifen (Willsher et al, 1998; Gregory et al, 2000). Immunohistochemical staining for $\mathrm{Ki}-67$, a nuclear antigen expressed in cycling cells, allows the proliferation index of tumours to be estimated on paraffinembedded tissue sections. Higher responses to chemotherapy have been reported in patients with rapidly proliferating tumours (Remvikos et al, 1989; Bottini et al, 1996; Collecchi et al, 1998), but other studies have failed to confirm this association (Silvestrini et al, 1987; Bonadonna et al, 1990; Makris et al, 1997; Ozmen et al, 2001).

The optimum method for assessing response to neoadjuvant chemotherapy is unclear. Clinical response has traditionally been used as a surrogate intermediate end point in biological marker studies although the NSABP-B18 trial, the largest randomised trial of PST to date, demonstrated that clinical response predicted disease-free but not overall survival (Fisher et al, 1997). However, recent reports from The Royal Marsden Hospital show that good clinical responders (patients with complete clinical response or residual thickening only) achieve superior overall survival at 10 years compared to poor clinical responders (Chang et al, 1999; Cleator et al, 2003). Radiological assessment by mammography and/or ultrasound has been used as a more objective measurement of response, but correlation with long-term survival has not been widely studied. Complete pathological response has consistently 
been shown to be associated with improved outcome, but only a small minority of patients display complete tumour regression after treatment, reducing its clinical utility as a biological end point (Sataloff et al, 1995). Patients who achieve a complete pathological response (pCR) have a statistically significantly superior survival compared to those with residual invasive carcinoma after PST (Fisher et al, 1998). Scoring systems that grade incomplete pathological responses have been devised but have not been consistently applied. In this study, therefore, a scoring system devised to grade pathological response has been used alongside traditional clinical and radiological end points. In the absence of an optimal method of response assessment, we adopted a pragmatic approach to measure response by clinical, radiological and pathological criteria to evaluate whether ER, PgR, HER-2 status or Ki-67 proliferation index before or after treatment predict response to anthracycline-based PST in women with primary breast cancer.

\section{MATERIALS AND METHODS}

\section{Treatment protocol}

During the period September 1995-September 1999, 118 patients with primary operable (T2-T4, N0 or $\mathrm{N} 1, \mathrm{M} 0)$ invasive primary breast carcinoma were identified (Table 1). Women with inflammatory breast cancer (T4d) or metastatic disease (M1) were excluded. All patients underwent diagnostic core biopsy of the breast tumour to confirm invasive carcinoma before commencing treatment. Bidimensional clinical tumour measurements were performed prior to every cycle of treatment. Radiological measurements of tumour size were recorded before and on

Table I Patient characteristics

\begin{tabular}{|c|c|c|}
\hline & $n$ & $\%$ \\
\hline Age: median (years) & 48 & \\
\hline Age: range (years) & $25-78$ & \\
\hline \multicolumn{3}{|l|}{ Menstrual status } \\
\hline Pre & 69 & 59 \\
\hline Peri & 19 & 16 \\
\hline Post & 30 & 25 \\
\hline \multicolumn{3}{|l|}{ Clinical TNM stage } \\
\hline $\mathrm{T} 2$ & 61 & 52 \\
\hline T3 & 42 & 36 \\
\hline T4 & 15 & 12 \\
\hline \multicolumn{3}{|l|}{ Clinical node status } \\
\hline No & 61 & 52 \\
\hline $\mathrm{NI}$ & 57 & 48 \\
\hline \multicolumn{3}{|l|}{ Tumour grade } \\
\hline Gl & 11 & 14 \\
\hline G2 & 35 & 44 \\
\hline G3 & 33 & 42 \\
\hline \multicolumn{3}{|l|}{ Breast } \\
\hline Right & 64 & 54 \\
\hline Left & 53 & 45 \\
\hline Bilateral & I & । \\
\hline \multicolumn{3}{|l|}{ Chemotherapy regimen } \\
\hline FEC & 91 & 77 \\
\hline$A C$ & 9 & 8 \\
\hline CAF & 2 & 2 \\
\hline ECF & 2 & 2 \\
\hline MMM & 14 & 12 \\
\hline
\end{tabular}

completion of chemotherapy in 94 patients by mammography and/ or breast ultrasound. Patients with responding or stable disease by clinical criteria received six cycles of anthracycline-based chemotherapy administered at 21-day intervals. Surgery was performed approximately 1 month after the final cycle of chemotherapy: 46 women had breast-conserving surgery, 55 required mastectomy and one patient underwent axillary dissection only. All patients managed by breast-conserving surgery received post-operative radiation to the residual breast $40 \mathrm{~Gy}$ in 15 daily fractions over 3 weeks plus $10 \mathrm{~Gy}$ boost to the tumour bed in five fractions; $n=32$ ); 14 patients also had the draining lymph node areas irradiated ( $50 \mathrm{~Gy}$ in 25 fractions over 5 weeks). Postmastectomy chest wall radiation was delivered to 46 of 55 patients (32 chest wall only, 14 chest wall and lymph nodes). No patient received postoperative chemotherapy. Women with ER + tumours received 5 years adjuvant Tamoxifen $(20 \mathrm{mg}$ daily) starting after surgery.

Five patients developed disease progression by clinical criteria; four proceeded to immediate surgery. The remaining patient progressed by clinical and radiological criteria after three cycles of FEC chemotherapy; she responded to four cycles of second-line docetaxel and had a near-complete pathological response at operation ( $1 \mathrm{~mm}$ residual invasive carcinoma). A group of 16 patients who attained a complete clinical and/or radiological response received radical radiotherapy to the breast and draining nodal areas, but no surgery. The local research and ethics committee approved the study prior to patient recruitment.

\section{Chemotherapy schedules}

Patients received a maximum of six cycles of chemotherapy at 21day intervals using one of the following regimens (see Table 1): 5 fluorouracil (5FU) $600 \mathrm{mg} \mathrm{m}^{-2}$, epirubicin $60 \mathrm{mg} \mathrm{m}^{-2}$, cyclophosphamide $600 \mathrm{mg} \mathrm{m}^{-2}$ (FEC); adriamycin $60 \mathrm{mg} \mathrm{m}^{-2}$, cyclophosphamide $600 \mathrm{mg} \mathrm{m}^{-2}$ (AC); cyclophosphamide $600 \mathrm{mg} \mathrm{m}^{-2}$, adriamycin $60 \mathrm{mg} \mathrm{m}^{-2}$, 5FU $600 \mathrm{mg} \mathrm{m}^{-2}$ (CAF); epirubicin $50 \mathrm{mg} \mathrm{m}^{-2}$, cisplatin $60 \mathrm{mg} \mathrm{m}^{-2}$; $5 \mathrm{FU} 200 \mathrm{mg} \mathrm{m}^{-2}$ day $^{-1}$ via Hickman line (ECF) or methotrexate $30 \mathrm{mg} \mathrm{m}^{-2}(\max 45 \mathrm{mg})$, mitoxantrone $7 \mathrm{mg} \mathrm{m}^{-2}$, mitomycin $\mathrm{C} 7 \mathrm{mg} \mathrm{m}^{-2}$ (alternate cycles only) (MMM).

\section{Assessment of response}

Clinical and radiological response Standard UICC criteria (Hayward et al, 1977) were used to categorise objective clinical and radiological response. Changes in the calculated product of bidimensional clinical (c) or radiological (r) tumour measurements at diagnosis and on completion of chemotherapy were recorded. Complete response (CR) was defined as no residual palpable or radiological abnormality; partial response (PR) as greater than $50 \%$ tumour shrinkage; stable disease (SD) as less than $50 \%$ tumour shrinkage or no change; progressive disease (PD) as an increase of at least $25 \%$.

Pathological response Many different grading systems for pathological response have been proposed (Chevallier et al, 1993; Sataloff et al, 1995; Akashi-Tanaka et al, 1996; Honkoop et al, 1998; Kuerer et al, 1998; Smith et al, 2000), but no standard method for pathological assessment after chemotherapy has been accepted. A novel simple scoring system designed to be applied in routine clinical practice was therefore devised. A consultant histopathologist (PIR) reviewed all surgical specimens for evidence of 'histological tumour response' defined by both (1) an apparent reduction in tumour cell:stroma ratio and (2) chemotherapyinduced cytological changes (enlarged cells with finely vacuolated cytoplasm, an enlarged vesicular nucleus with a prominent single eosinophilic nucleolus, or an enlarged hyperchromatic dense 
nucleus with an irregular outline). The following classification was used to score histological specimens for pathological response: pCR - no residual invasive carcinoma; pPR - residual invasive carcinoma with histological tumour response; pSD - residual invasive carcinoma with no histological tumour response. Adequate material from the resected tumour was available for pathological assessment for 99 of the 102 patients who proceeded to surgery.

\section{Immunohistochemical technique}

Immunohistochemical staining for ER, PgR, HER-2 and Ki-67 was performed on sections of formalin-fixed paraffin-embedded tissue from core biopsies and subsequent surgical specimens mounted on poly-L-lysine slides. Slides were dewaxed and then rehydrated through graded alcohol $(90,50$ and $20 \%)$. Following microwave pre-treatment in $10 \mathrm{~mm}$ citric acid, monoclonal mouse antibody to ER, PgR, HER-2 or Ki-67 was applied for $60 \mathrm{~min}$ at room temperature using the following dilutions: anti-ER - 1:40, antiPgR - 1:60 (Novocastra Laboratories, UK); pre-diluted anti-HER2 (Zymed Laboratories, San Francisco, CA, USA); anti-Ki-67 1:200 (DAKO Laboratories, UK). Following three rinses in trisbuffered saline (TBS) and incubation with the secondary antibody, positive brown staining was detected using a standard avidin and biotinylated horseradish peroxidase $(\mathrm{ABC})$ technique with $3,3^{\prime}$ diaminobenzidine $(\mathrm{DAB})$ as the chromogen. Slides were then counterstained in Mayer's haematoxylin for $10 \mathrm{~s}$, dehydrated in graded alcohol, mounted and scored. Positive and negative controls were performed with each stain and paired core biopsies and surgical specimens from the same patient were stained on the same run.

\section{Scoring methods}

Immunohistochemical scoring was performed, blinded to clinical and radiological response, using the systems described below.

$E R$ and $P g R$ A validated semi-quantitative scoring system (the 'Allred score') was used to assess the proportion $(0=$ nil, $1<1 / 100$, $2<1 / 10,3<1 / 3,4<2 / 3,5>2 / 3)$ and intensity $(0=$ no staining, $1=$ weak, 2 = intermediate, $3=$ strong) of stained cells (Allred $e t a l$, 1990). A total score (range $0,2-8$ ) of 3 or more defined positive staining.

HER-2 A standard scoring system to assess both the intensity and proportion of membrane staining was used: 0 - no membrane staining or membrane staining in less than $10 \%$ of tumour cells; $1^{+}$- faint barely perceptible membrane staining in more than $10 \%$ of tumour cells visible in part of the membrane only; $2^{+}-$weak to moderate staining of the entire membrane in more than $10 \%$ of tumour cells; $3^{+}-$strong staining of the entire membrane in more than $10 \%$ of tumour cells. Tumours scored $3+$ were classed positive.

Ki-67 Positive and negatively stained cells were counted on a minimum of 10 randomly selected $\times 40$ high-power fields containing representative sections of tumour. The Ki-67 proliferation index (the fraction of proliferating cells) was calculated (i.e. number of positively stained cells as a percentage of the total cell count).

\section{Statistical methods}

Statistical analysis was carried out using JMP version 5.0. (SAS Institute Inc.). Associations between ordinal variables were assessed using $\chi^{2}$ analyses or the Fischer Exact Test in the case of $2 \times 2$ variables. Analyses involving Ki-67 as a continuous variable were investigated using ANOVA.

\section{RESULTS}

\section{Response rates}

A median of six cycles of chemotherapy was administered (range 2-6). At the time of analysis, 118, 94 and 99 patients were evaluable for clinical, radiological and pathological response, respectively. The overall objective clinical and radiological response rates $(\mathrm{CR}+\mathrm{PR})$ to preoperative chemotherapy were 78 and $72 \%$, respectively. In all, $40 \%$ of patients attained a clinical CR. However, the pathological response rate was just $38 \%$, including eight complete pathological responders (8\%) among 99 assessable patients. Of the eight patients who achieved a complete pathological response, one was classified as a partial clinical and radiological responder and a further two achieved a partial radiological response; the remainder were complete responders by nonpathological criteria. Eight patients (7\%) developed progressive disease during chemotherapy by clinical (five) and/ or radiological (five) criteria; all the remaining 29 women had stable disease on clinical (21) and/or imaging (21) assessments (Table 2).

Figure 1 shows the relationships between the three response end points and illustrates that significant difference in response categorisation exists depending on the chosen end point. However, when the clinical and worst radiological response data (ultrasound or mammography) were condensed to responders (CR or PR) vs nonresponders (SD or PD), there was almost complete agreement $(98.5 \%)$ in classification of responders but a third of radiological nonresponders had a clinical response.

\section{Pretreatment biological parameters: inter-relationships and correlation with clinico-pathological features}

The median positivity for Ki-67 was $24.9 \%$. (range $4.1-58.5 \%$ ). There was a wide range of expression patterns for ER and PgR. Overall, $63.6 \%$ of tumours were classified as ER + and $55.1 \%$ were $\mathrm{PgR}+$. The majority of $\mathrm{ER}+(77 \%)$ and $\mathrm{PgR}+(58 \%)$ specimens showed expression in greater than $\frac{1}{3}$ of cells with a wide range of staining intensity; this resulted in a wide variation in the total Allred score spanning all categories from 2 to 8 (data not shown). Positive $(3+)$ HER-2 staining was seen in $16 \%$ of tumours; 15 tumours $(13 \%)$ showed weak to moderate staining $(2+)$ deemed negative for the purpose of these analyses.

The inter-relationships between the four biological markers, pretreatment tumour size and pathological node status are shown in Table 3. There was a significant correlation between ER and PgR

Table 2 Response rates [n (\%)] by method of assessment

\begin{tabular}{|c|c|c|c|c|c|c|}
\hline Assessment & $n$ & ORR $\mathbf{R}^{\mathrm{a}}$ & CR & PR & SD & PD \\
\hline Clinical & 118 & 92 (78\%) & 47 (40\%) & 45 (38\%) & $21(18 \%)$ & $5(4 \%)$ \\
\hline Radiological & 94 & 68 (72\%) & $18(19 \%)$ & $50(53 \%)$ & $21(22 \%)$ & $5(5 \%)$ \\
\hline
\end{tabular}

${ }^{a} \mathrm{ORR}$ : overall response rate $=\mathrm{CR}+\mathrm{PR}$. 


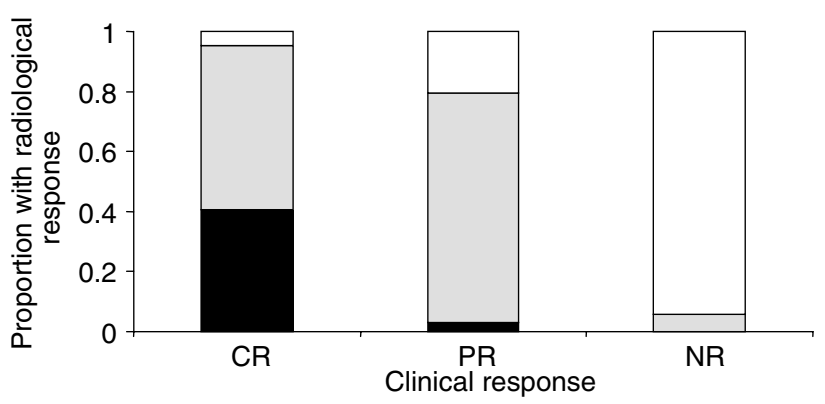

Table 4 Response rates ( $C R+P R)$ by biopsy marker status

\begin{tabular}{lccc}
\hline & $\begin{array}{c}\text { Clinical } \\
\text { response (\%) }\end{array}$ & $\begin{array}{c}\text { Radiological } \\
\text { response (\%) }\end{array}$ & $\begin{array}{c}\text { Pathological } \\
\text { response (\%) }\end{array}$ \\
\hline All patients & 78 & 72 & 38 \\
ER+ & 81 & 73 & 34 \\
ER- & 72 & 71 & 46 \\
P-value & 0.25 & 0.81 & 0.29 \\
PgR+ & 83 & 78 & 31 \\
PgR- & 72 & 65 & 47 \\
P-value & 0.18 & 0.17 & 0.15 \\
& & & \\
HER-2+ & 71 & 62 & 44 \\
HER-2- & 81 & 77 & 36 \\
P-value & 0.23 & 0.15 & 0.51 \\
& & & \\
Ki-67 high & 73 & 74 & 39 \\
Ki-67 low & 81 & 0.81 & 38 \\
P-value & 0.38 & 1.0 \\
\hline
\end{tabular}

Each parameter was dichotomised as described in the text or above and below the median value for $\mathrm{Ki}-67$.

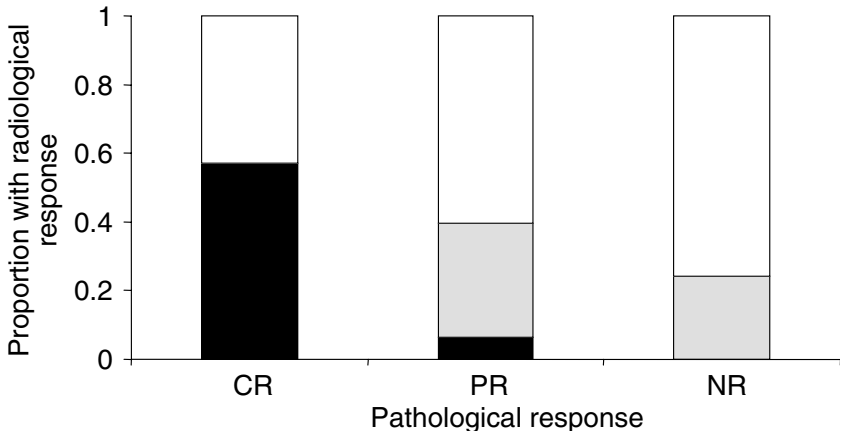

Figure I Correlation between clinical, radiological and pathological response. Solid bars represent CR; shaded bars PR and open bars NR.

Table 3 Relationship between clinical and biological variables

\begin{tabular}{lccc}
\hline & \multicolumn{1}{c}{ T2 } & T3/4 & P \\
\hline ER+ & $39 / 61(64.0 \%)$ & $36 / 57(63.2 \%)$ & NS \\
PgR+ & $34 / 61(55.7 \%)$ & $31 / 57(54.4 \%)$ & NS \\
HER-2+ & $21 / 61(34.4 \%)$ & $13 / 57(22.8 \%)$ & NS \\
Ki-67 median & $25.8 \%$ & $23.1 \%$ & NS
\end{tabular}

ER- $\quad$ ER+

\begin{tabular}{lccc}
\hline PgR+ & $9 / 43(20.9 \%)$ & $56 / 75(74.7 \%)$ & $<0.0001$ \\
HER-2+ & $14 / 43(32.6 \%)$ & $20 / 75(26.7 \%)$ & NS \\
Ki-67 median & $28.6 \%$ & $23.1 \%$ & NS
\end{tabular}

Ki-67 median

$28.6 \%$

HER-2+

HER-2 -

\begin{tabular}{lccc}
\hline ER+ & $55 / 84(65.5 \%)$ & $20 / 34(58.8 \%)$ & NS \\
PgR+ & $49 / 84(58.3 \%)$ & $16 / 34(47.1 \%)$ & NS \\
Ki-67 median & $25.4 \%$ & $23.5 \%$ & NS
\end{tabular}

\begin{tabular}{llll} 
& PgR - & PgR+ & \\
\hline Ki-67 median & $28.3 \%$ & $22.9 \%$ & 0.04 \\
\hline
\end{tabular}

$(P<0.0001): 80 \%$ of ER - tumours were also PgR-; $75 \%$ of tumours showed positivity for both steroid receptors. Higher Ki-67 proliferation indices were associated with $\mathrm{PgR}-$ tumours
(PgR - median 28.3\%, PgR $+22.9 \% ; P=0.04)$. A nonsignificant trend towards higher cell proliferation in pathologically nodepositive tumours was observed (pathologically node negative, median Ki-67 19.6\%, node positive $25.8 \%$; $P=0.09$ ). There were no relationships between HER-2 expression and the other biological markers.

No relationship was seen between hormone receptor status and primary tumour size or pretreatment lymph node involvement. Ki67 proliferation index was similar in both small and larger tumours. Clinically, node-negative patients (23 out of 61 ) were more likely to overexpress HER-2 than node-positive tumours (11 out of $57 ; P=0.04$ ) (data not shown).

\section{Pretreatment biological parameters: correlation with treatment response}

None of the pretreatment biopsy parameters correlated with any clinical, radiological or pathological response measures (Table 4). Combining the biological parameters into 'good' (ER + and $\mathrm{PgR}+$, low Ki-67) or 'bad' (ER- and PgR-, high Ki-67) risk prognostic groups also had no impact in predicting clinical response (data not shown).

\section{Changes in biological parameters during treatment}

Figure 2 shows the changes in each biological parameter after PST. The steroid receptors showed only modest alterations during treatment. Only 13 and 25 tumours showed a shift in ER or PgR Allred score of more than 1 , respectively. This resulted in three tumours changing their ER classification (positive to negative or vice versa), while seven specimens showed re-classification of their overall PgR score after chemotherapy. The median Ki-67 proliferation indices before and after treatment were 24.9 and $18.1 \%$, respectively $(P=0.002)$. Expressing the change as a function of the pretreatment Ki-67 index resulted in a median reduction in $\mathrm{Ki}-67$ index after treatment of $21.2 \%$. Of 84 evaluable patients, $47(60 \%)$ showed little or no change $( \pm 10 \%$ of $\%$ change), 10 patients (12\%) showed an increase of $>50 \%$ of the original index and $24(29 \%)$ showed a reduction of $>50 \%$. Strong or moderate HER-2 staining $(2+$ or $3+)$ at diagnosis persisted in every case after chemotherapy although HER-2 positivity $(3+$ cases only) changed in nine cases: five $2+$ tumours were scored $3+$ at operation and four $3+$ tumours reverted to $2+$ at surgery. 

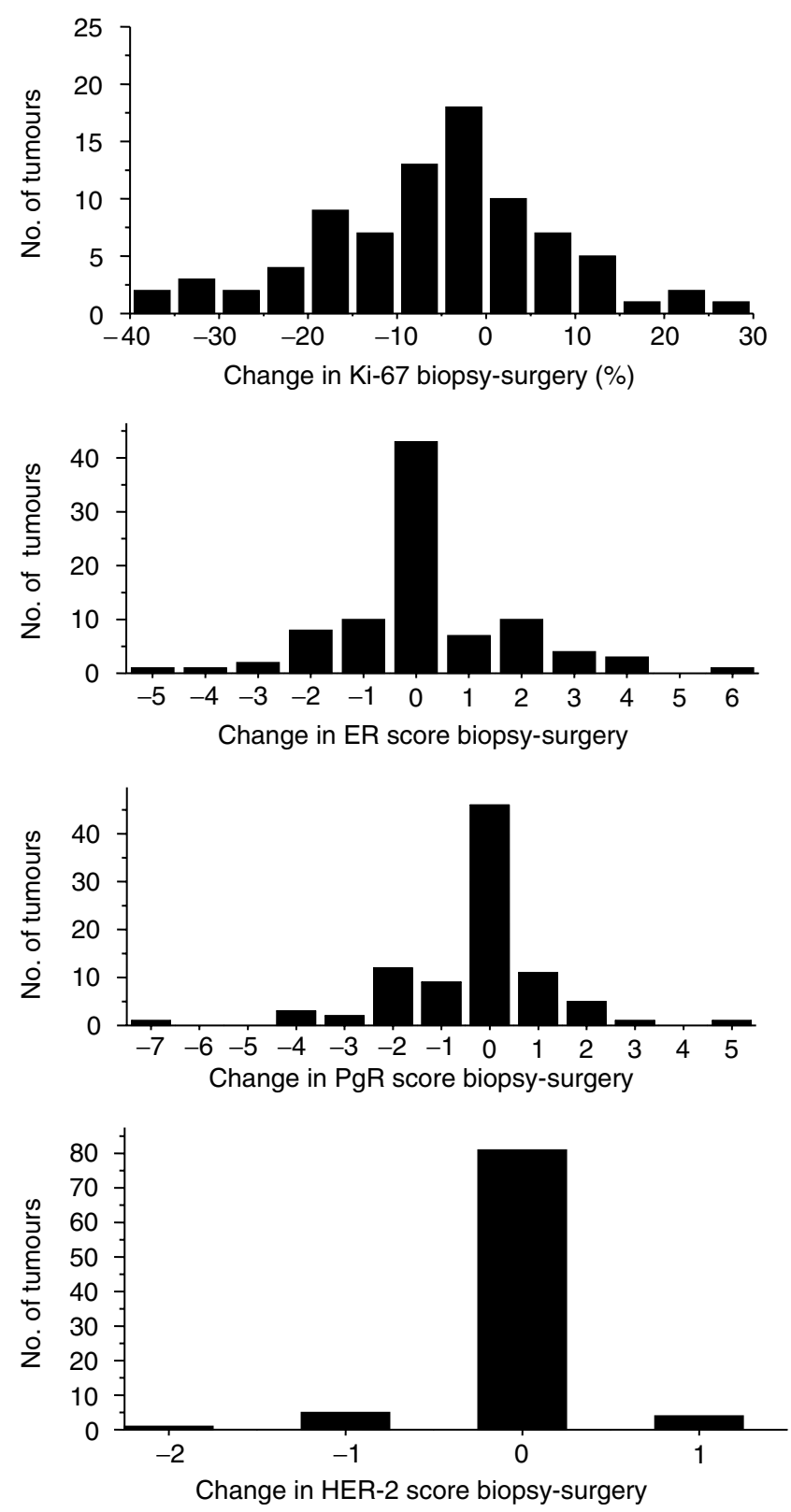

Figure 2 Graphical representation of change in marker status after treatment.

\section{Post-treatment biological parameters: correlation with treatment response}

None of the biological markers measured in the surgical specimen correlated with any of the treatment response end points.

\section{Changes in biological parameters: correlation with treatment response}

Changes in hormone receptor status or HER-2 did not predict treatment response by pathological, clinical or radiological criteria. Overall, there was no significant difference in the reduction in Ki67 after treatment between responders and nonresponders when assessed by clinical, radiological or pathological criteria. However, patients with the greatest reduction in cell proliferation after chemotherapy were more likely to achieve a pathological response. Of the nine patients displaying a $75 \%$ or more fall in Ki-67 index after treatment, seven (77.8\%) were pathological responders; conversely, only 20 of the remaining 75 evaluable patients (26.7\%) with less extreme decreases in cell proliferation responded by histological criteria $(P=0.004)$.

\section{DISCUSSION}

The identification of reliable predictive and prognostic factors for PST in operable breast cancer remains a challenge. In the same way that ER and PgR status can predict sensitivity to endocrine therapy, reliable markers of chemosensitivity would help select those patients most likely to benefit from primary chemotherapy. More importantly, the early identification of nonresponders would allow these patients to be spared the unnecessary toxicity of ineffective chemotherapy and be offered alternative more effective treatment regimens tailored to the biological characteristics of the tumour.

Previous studies have focused on the ability to predict clinical tumour shrinkage, despite the fact that local response is a crude measure dependent on several variables including primary tumour size, oedema, necrosis and subjective variation in tumour measurements. Clinical assessment frequently overestimates tumour size (Fornage et al, 1987; Pain et al, 1992; Forouhi et al, 1994; Meden et al, 1995; Allen et al, 2001). Radiological assessment of maximum tumour dimensions by ultrasound or mammography is often performed to assess response and correlates better with histological tumour size than clinical measurements (Allen et al, 2001; Fiorentino et al, 2001). However, complete pathological response is the best predictor of long-term survival (Fisher et al, 1998). In the absence of a universally accepted optimal end point, this study therefore analysed the ability of simple biological markers to predict clinical, radiological and pathological response to treatment.

The clinical response $(\mathrm{CR}+\mathrm{PR})$ and complete pathological response (pCR) rates of 78 and $8 \%$, respectively, seen in this series are consistent with those reported in larger randomised trials of PST (Bonadonna et al, 1990; Mauriac et al, 1991; Belembaogo et al, 1992; Fisher et al, 1997; Makris et al, 1998). The rates of positive staining for ER, PgR, HER-2 and Ki67 are also in accordance with expectations. Steroid hormone receptor status, HER-2 staining and Ki-67 index did not vary with tumour size or lymph node involvement, in keeping with previous observations (Bouzubar et al, 1989; Bottini et al, 1996).

In contrast with previous reports (Bonadonna et al, 1990; Bottini et al, 1996; Chang et al, 1999; Colleoni et al, 2000), clinical response rates to PST were higher in hormone receptor-positive tumours in this cohort, although the difference did not reach statistical significance. It is worthy of note that patients with hormone receptor-positive tumours in this study received chemotherapy followed by sequential adjuvant tamoxifen, rather than primary concurrent chemoendocrine treatment used in earlier reports (Makris et al, 1998; Chang et al, 1999). Consequently, any observed changes in marker status must be attributed to the direct effects of chemotherapy alone since the confounding influence of synchronous endocrine treatment has been excluded.

There is some evidence from prospective studies that HER-2 overexpression predicts sensitivity to adjuvant anthracycline chemotherapy (Muss et al, 1994; Clahsen et al, 1998; Paik et al, 1998; Thor et al, 1998) and resistance to tamoxifen (Nicholson $e t$ al, 1993; Leitzel et al, 1995; Carlomagno et al, 1996; Yamauchi et al, 1997). However, in this series, a nonsignificant trend towards poorer clinical and radiological response was seen in HER-2 overexpressors, although no difference in pathological response rates was observed. HER-2 expression was more common in ERtumours (33 vs 27\%) although the difference did not reach statistical significance. It should be noted that the dose of epirubicin used in this study $\left(60 \mathrm{mg} \mathrm{m}^{-2}\right)$ may be considered 
suboptimal, particularly for HER-2 + tumours. However, this was the standard dose in our institution at the time of the study.

These data confirm that no single pretreatment or postchemotherapy biological parameter predicts response by clinical, radiological or pathological criteria. With longer follow-up, it will be possible to correlate response by the three different assessment modalities with long-term survival and ultimately decide which, if any, of the methods of assessing response is best placed to act as a surrogate marker for overall survival in this cohort.

It is unlikely that any single biological marker will ever be able to reliably discriminate between responders and nonresponders, but combinations of marker expression may have greater predictive value. Intuitively, steroid receptor-negative tumours with a high proliferative rate may be expected to confer a worse prognosis. In order to test this hypothesis, we arbitrarily grouped tumours into those with a combination of 'good' (ER + and $\mathrm{PgR}+$, low Ki-67) or 'bad' (ER- and PgR - and high Ki-67) biological parameters. However, these arbitrary groups of markers also failed to discriminate between responders and nonresponders.

Although the potential effects of PST on the biological characteristics of primary breast cancers have not been widely studied, clinical decisions regarding adjuvant treatment after primary chemotherapy are frequently based on immunohistochemical analysis performed on surgical specimens pretreated with cytotoxic therapy. In this series, negative ( 0 or 1$)$ and strong or moderate $(2+$ or $3+)$ HER-2 staining persisted after chemotherapy in every case. This is consistent with earlier observations that HER-2 status remains unchanged after PST (Bottini et al, 1996; Taucher et al, 2003b). In this series, some subtle changes in HER-2 staining were seen after chemotherapy. In nine of 118 cases (8\%), HER-2 status changed from positive to negative or vice versa (five cases $2+$ to $3+$; four tumours $3+$ to $2+$ ). Based on these data, we recommend that patients with HER-2 scores of 0 or 1 on pretreatment biopsies do not require repeat assay after chemotherapy; however, patients with moderate or strong staining should undergo FISH analysis on a post-treatment tissue block to accurately determine the post-chemotherapy HER-2 status.

Hormone receptor expression was unchanged after treatment in the majority of tumours in this cohort, but a significant minority (10 cases, 8\%) displayed a shift in ER or PgR classification at the time of surgery. In five of the 10 tumours in which changes in receptor status were described, negative staining on pretreatment core biopsies was scored positive after chemotherapy. In the remaining five cases, hormone receptor-positive core biopsies stained negative at operation. Although these observations may reflect sampling error within heterogeneous tumours, immunostaining on needle core biopsies in a previously reported series of 236 patients treated without intervening chemotherapy was highly representative of hormone receptor status in the entire resected tumour (Taucher et al, 2003a), suggesting that sampling error does not account for the observed hormone receptor 'upregulation' seen in some cases.

Some groups investigating the modulation of steroid receptor status by PST reported no significant changes in ER or PgR (Hawkins et al, 1990; Bottini et al, 1996; Schneider et al, 2000) after primary chemotherapy. The data presented here concur with two earlier small studies in which 10\% (Lo et al, 1994) and 33\% (Jain et al, 1996) of breast cancers expressed altered steroid receptor status after PST. A recently published comprehensive analysis of hormone receptor immunochemistry in 450 breast cancer patients confirmed these observations in a larger cohort and speculated on a possible hypothesis for the mechanism of changes in ER and PgR status after PST (Taucher et al, 2003a). Among 191 patients receiving PST, 14 of 100 ER + tumours (14\%) stained ER- after treatment, representing a statistically significant shift of ER + to ER - status as a direct result of PST $(P=0.02)$. Half of these patients (7 out of 14) were pre-menopausal, suggesting that PST may be exerting an endocrine effect by rendering women post- menopausal after chemotherapy. Our data are consistent with this hypothesis: four of the five patients displaying decreases in hormone receptor positivity after chemotherapy were premenopausal at diagnosis. Since potentially curative adjuvant hormone therapy is prescribed on the basis of hormone receptor immunostaining, we recommend that patients with ER- or PgRstatus on pretreatment core biopsies should undergo repeat assay on the resected surgical specimen.

The observation that the median Ki-67 index was significantly lower after treatment in this cohort suggests that chemotherapy is exerting a true anti-proliferative effect on tumours in vivo. Both primary endocrine (Clarke et al, 1993) and cytotoxic treatments (Daidone et al, 1991; Gardin et al, 1994) inhibit tumour growth. Tumour cell proliferation has been shown to be a prognostic marker in some reports (Remvikos et al, 1989; Bonetti et al, 1996; Chevillard et al, 1996), but data on its predictive value are conflicting. S-phase fraction, proliferating cell nuclear antigen and thymidine labelling index predict overall survival (Clayton, 1991; Fisher et al, 1991; Merkel et al, 1993) and response (Collecchi et al, 1996; Bottini et al, 1998; Nishimura et al, 2002), but not diseasefree survival (Bianchi et al, 1993; Pisansky et al, 1993; Tahan et al, 1993 ) in patients treated with primary surgery or chemotherapy.

Baseline Ki-67 index did not predict clinical response in this cohort of patients. This is consistent with other studies (Bonadonna et al, 1990; Makris et al, 1997), but in contrast to data from other groups, which suggested that S-phase fraction (Remvikos et al, 1989), Ki-67 index (Bottini et al, 1996) or thymidine labelling index (Collecchi et al, 1998) predict clinical tumour shrinkage. To the best of our knowledge, pathological response has not been formally assessed in previous studies analysing the predictive value of Ki-67 before and after PST. In this study, pretreatment cell proliferation failed to predict pathological response. This suggests that chemosensitivity is not simply a function of the baseline rate of tumour cell proliferation, and supports the theory that some rapidly proliferating tumours are inherently chemoresistant. However, tumours that displayed a large reduction in Ki-67 index after chemotherapy were more likely to achieve a pathological response: $78 \%$ of patients (seven out of nine) with falls of $>75 \%$ in $\mathrm{Ki}-67$ after treatment were pathological responders compared to 20 out of 75 (27\%) of those with less extreme falls in Ki-67. These findings have not been previously reported. Intuitively, this observation suggests that the antiproliferative and proapoptotic effects of chemotherapy are indeed translated into a measurable histological response.

Like many studies in this field, this work is hindered by the fact that complete pathological response and clinical progression - the two scenarios that clinicians would most like to be able to predict are relatively uncommon events. The majority of patients achieve a PR by clinical or radiological criteria and nearly two-thirds showed SD by pathological assessment. Consequently, large studies are required if reliable predictive markers are to be identified.

In conclusion, the baseline biological characteristics of primary breast tumours analysed in this study did not predict response to treatment by any modality of assessment. However, patients with the greatest reductions in tumour cell proliferation on completion of chemotherapy were most likely to achieve a pathological response. With longer follow-up, it will be possible to establish if chemotherapy-induced changes in cell proliferation have prognostic value, and to determine whether the pathological response scoring system described here can be used as a surrogate end point for long-term clinical outcome.

Novel markers that relate to the actions of chemotherapy drugs are needed if reliable predictive markers are to be identified. One such example is topoisomerase II $\alpha$, a molecular target for anthracyclines. A recent study showed that strong topoisomerase II $\alpha$ staining is an independent predictor of clinical tumour regression (MacGrogan et al, 2003); a confirmatory study is underway on this data set. In the meantime, it is imperative that 
large ongoing randomised clinical trials of new PST regimens encourage recruitment into parallel biological marker studies so that more powerful data sets can continue the search for favourable and unfavourable biological profiles that may ultimately help clinicians individualise treatments. Meanwhile, the ability to study the patterns of expression of thousands of candidate genes simultaneously using new micro-array technologies (Perou et al, 2000; Chang et al, 2003) may rapidly surpass

\section{REFERENCES}

Akashi-Tanaka S, Tsuda H, Fukuda H, Watanabe T, Fukutomi T (1996) Prognostic value of histopathological therapeutic effects and mitotic index in locally advanced breast cancers after neoadjuvant chemotherapy. Jpn J Clin Oncol 26: $201-206$

Allen S, Cunliffe W, Gray J, Liston J, Lunt L, Webb L, Young J (2001) Preoperative estimation of primary breast cancer size: a comparison of clinical assessment, mammography and ultrasound. Breast 10: 299-305

Allred DC, Bustamante MA, Daniel CO, Gaskill HV, Cruz Jr AB (1990) Immunocytochemical analysis of estrogen receptors in human breast carcinomas. Evaluation of 130 cases and review of the literature regarding concordance with biochemical assay and clinical relevance. Arch Surg 125: $107-113$

Allred DC, Harvey JM, Berardo M, Clark GM (1998) Prognostic and predictive factors in breast cancer by immunohistochemical analysis. Mod Pathol 11: 155-168

Belembaogo E, Feillel V, Chollet P, Cure H, Verrelle P, Kwiatkowski F, Achard JL, Le Bouedec G, Chassagne J, Bignon YJ, De Latour M, Lafaye C, Dauplat J (1992) Neoadjuvant chemotherapy in 126 operable breast cancers. Eur J Cancer 28A: 896-900

Bianchi S, Paglierani M, Zampi G, Cardona G, Cataliotti L, Bonardi R, Zappa M, Ciatto S (1993) Prognostic value of proliferating cell nuclear antigen in lymph node-negative breast cancer patients. Cancer 72: $120-125$

Bonadonna G, Veronesi U, Brambilla C, Ferrari L, Luini A, Greco M, Bartoli C, Coopmans de Yoldi G, Zucali R, Rilke F, Andreola S, Silvestrini R, Di Fronzo G, Valagussa P (1990) Primary chemotherapy to avoid mastectomy in tumors with diameters of three centimeters or more. J Natl Cancer Inst 82: 1539-1545

Bonetti A, Zaninelli M, Rodella S, Molino A, Sperotto L, Piubello Q, Bonetti F, Nortilli R, Turazza M, Cetto GL (1996) Tumor proliferative activity and response to first-line chemotherapy in advanced breast carcinoma. Breast Cancer Res Treat 38: 289-297

Bottini A, Berruti A, Bersiga A, Brunelli A, Brizzi MP, Di Marco B, Cirillo F, Tampellini M, Bolsi G, Aguggini S, Betri E, Filippini L, Bertoli A, Alquati P, Dogliotti L (1998) Cytotoxic and antiproliferative activity of the CMF regimen administered in association with tamoxifen as primary chemotherapy in breast cancer patients. Int J Oncol 13: $385-390$

Bottini A, Berruti A, Bersiga A, Brunelli A, Brizzi MP, Marco BD, Cirillo F, Bolsi G, Bertoli G, Alquati P, Dogliotti L (1996) Effect of neoadjuvant chemotherapy on Ki67 labelling index, c-erbB-2 expression and steroid hormone receptor status in human breast tumours. Anticancer Res 16: $3105-3110$

Bouzubar N, Walker KJ, Griffiths K, Ellis IO, Elston CW, Robertson JF, Blamey RW, Nicholson RI (1989) Ki67 immunostaining in primary breast cancer: pathological and clinical associations. $\mathrm{Br} J$ Cancer 59: $943-947$

Carlomagno C, Perrone F, Gallo C, De Laurentiis M, Lauria R, Morabito A, Pettinato G, Panico L, D'Antonio A, Bianco AR, De Placido S (1996) c-erb B2 overexpression decreases the benefit of adjuvant tamoxifen in earlystage breast cancer without axillary lymph node metastases. J Clin Oncol 14: $2702-2708$

Chang J, Powles TJ, Allred DC, Ashley SE, Clark GM, Makris A, Assersohn L, Gregory RK, Osborne CK, Dowsett M (1999) Biologic markers as predictors of clinical outcome from systemic therapy for primary operable breast cancer. J Clin Oncol 17: 3058-3063

Chang JC, Wooten EC, Tsimelzon A, Hilsenbeck SG, Gutierrez MC, Elledge R, Mohsin S, Osborne CK, Chamness GC, Allred DC, O’Connell P (2003) Gene expression profiling for the prediction of therapeutic response to docetaxel in patients with breast cancer. Lancet 362: 362-369

Chevallier B, Roche H, Olivier JP, Chollet P, Hurteloup P (1993) Inflammatory breast cancer. Pilot study of intensive induction retrospective analyses using immunohistochemistry in the continuing search for predictive and prognostic factors.

\section{ACKNOWLEDGEMENTS}

The Breast Cancer Research Trust and The Peel Trust generously supported this work. chemotherapy (FEC-HD) results in a high histologic response rate. Am J Clin Oncol 16: 223-228

Chevillard S, Pouillart P, Beldjord C, Asselain B, Beuzeboc P, Magdelenat H, Vielh P (1996) Sequential assessment of multidrug resistance phenotype and measurement of S-phase fraction as predictive markers of breast cancer response to neoadjuvant chemotherapy. Cancer 77: 292-300

Clahsen PC, van de Velde CJ, Duval C, Pallud C, Mandard AM, DelobelleDeroide A, van den Broek L, Sahmoud TM, van de Vijver MJ (1998) p53 protein accumulation and response to adjuvant chemotherapy in premenopausal women with node-negative early breast cancer. J Clin Oncol 16: $470-479$

Clarke RB, Laidlaw IJ, Jones LJ, Howell A, Anderson E (1993) Effect of tamoxifen on Ki67 labelling index in human breast tumours and its relationship to oestrogen and progesterone receptor status. Br J Cancer 67: $606-611$

Clayton F (1991) Pathologic correlates of survival in 378 lymph nodenegative infiltrating ductal breast carcinomas. Mitotic count is the best single predictor. Cancer 68: 1309-1317

Cleator S, Lal K, Ashley S, Makris A, Powles T (2003) Good clinical response by breast cancers to neoadjuvant chemoendocrine therapy is associated with superior overall survival after 10 years follow-up. Proc San Antonio Breast Cancer Symposium Abstract 231

Collecchi P, Baldini E, Giannessi P, Naccarato AG, Passoni A, Gardin G, Roncella M, Evangelista G, Bevilacqua G, Conte PF (1998) Primary chemotherapy in locally advanced breast cancer (LABC): effects on tumour proliferative activity, bcl-2 expression and the relationship between tumour regression and biological markers. Eur J Cancer 34: $1701-1704$

Collecchi P, Giannessi PG, Baldini E, Naccarato AG, Passoni A, Bevilacqua G, Conte PF (1996) Effects of primary chemotherapy on biological parameters of locally advanced breast cancer. Ann N Y Acad Sci 784: $419-426$

Colleoni M, Minchella I, Mazzarol G, Nole F, Peruzzotti G, Rocca A, Viale G, Orlando L, Ferretti G, Curigliano G, Veronesi P, Intra M, Goldhirsch A (2000) Response to primary chemotherapy in breast cancer patients with tumors not expressing estrogen and progesterone receptors. Ann Oncol 11: $1057-1059$

Daidone MG, Silvestrini R, Valentinis B, Ferrari L, Bartoli C (1991) Changes in cell kinetics induced by primary chemotherapy in breast cancer. Int $J$ Cancer 47: 380 - 383

EBCTCG (1998) Tamoxifen for early breast cancer: an overview of the randomised trials. Early Breast Cancer Trialists' Collaborative Group. Lancet 351: $1451-1467$

Fiorentino C, Berruti A, Bottini A, Bodini M, Brizzi MP, Brunelli A, Marini U, Allevi G, Aguggini S, Tira A, Alquati P, Olivetti L, Dogliotti L (2001) Accuracy of mammography and echography versus clinical palpation in the assessment of response to primary chemotherapy in breast cancer patients with operable disease. Breast Cancer Res Treat 69: 143-151

Fisher B, Brown A, Mamounas E, Wieand S, Robidoux A, Margolese RG, Cruz Jr AB, Fisher ER, Wickerham DL, Wolmark N, DeCillis A, Hoehn JL, Lees AW, Dimitrov NV (1997) Effect of preoperative chemotherapy on local-regional disease in women with operable breast cancer: findings from National Surgical Adjuvant Breast and Bowel Project B-18 (see comments). J Clin Oncol 15: 2483-2493

Fisher B, Bryant J, Wolmark N, Mamounas E, Brown A, Fisher ER, Wickerham DL, Begovic M, DeCillis A, Robidoux A, Margolese RG, Cruz Jr AB, Hoehn JL, Lees AW, Dimitrov NV, Bear HD (1998) Effect of preoperative chemotherapy on the outcome of women with operable breast cancer. J Clin Oncol 16: 2672-2685

Fisher B, Gunduz N, Costantino J, Fisher ER, Redmond C, Mamounas EP, Siderits R (1991) DNA flow cytometric analysis of primary operable 
breast cancer. Relation of ploidy and S-phase fraction to outcome of patients in NSABP B-04. Cancer 68: 1465-1475

Fornage BD, Toubas O, Morel M (1987) Clinical, mammographic, and sonographic determination of preoperative breast cancer size. Cancer 60: $765-771$

Forouhi P, Walsh JS, Anderson TJ, Chetty U (1994) Ultrasonography as a method of measuring breast tumour size and monitoring response to primary systemic treatment. Br J Surg 81: 223-225

Gardin G, Alama A, Rosso R, Campora E, Repetto L, Pronzato P, Merlini L, Naso C, Camoriano A, Meazza R, Barbieri F, Baldini E, Giannessi PG, Conte PF (1994) Relationship of variations in tumor cell kinetics induced by primary chemotherapy to tumor regression and prognosis in locally advanced breast cancer. Breast Cancer Res Treat 32: 311-318

Gregory RK, Powles TJ, Salter J, Chang JC, Ashley S, Dowsett M (2000) Prognostic relevance of cerbB2 expression following neoadjuvant chemotherapy in patients in a randomised trial of neoadjuvant versus adjuvant chemoendocrine therapy. Breast Cancer Res Treat 59: $171-175$

Harvey JM, Clark GM, Osborne CK, Allred DC (1999) Estrogen receptor status by immunohistochemistry is superior to the ligand-binding assay for predicting response to adjuvant endocrine therapy in breast cancer. J Clin Oncol 17: 1474-1481

Hawkins RA, Tesdale AL, Anderson ED, Levack PA, Chetty U, Forrest AP (1990) Does the oestrogen receptor concentration of a breast cancer change during systemic therapy? Br J Cancer 61: 877-880

Hayward JL, Carbone PP, Heuson JC, Kumaoka S, Segaloff A, Rubens RD (1977) Assessment of response to therapy in advanced breast cancer: a project of the Programme on Clinical Oncology of the International Union Against Cancer, Geneva, Switzerland. Cancer 39: 1289-1294

Honkoop AH, van Diest PJ, de Jong JS, Linn SC, Giaccone G, Hoekman K, Wagstaff J, Pinedo HM (1998) Prognostic role of clinical, pathological and biological characteristics in patients with locally advanced breast cancer. Br J Cancer 77: 621 - 626

Jain V, Landry M, Levine EA (1996) The stability of estrogen and progesterone receptors in patients receiving preoperative chemotherapy for locally advanced breast carcinoma. Am Surg 62: 162-165

Kiang DT, Frenning DH, Goldman AI, Ascensao VF, Kennedy BJ (1978) Estrogen receptors and responses to chemotherapy and hormonal therapy in advanced breast cancer. $N$ Engl J Med 299: 1330 - 1334

Kuerer HM, Newman LA, Buzdar AU, Dhingra K, Hunt KK, Buchholz TA, Binkley SM, Strom EA, Ames FC, Ross MI, Feig BW, McNeese MD, Hortobagyi GN, Singletary SE (1998) Pathologic tumor response in the breast following neoadjuvant chemotherapy predicts axillary lymph node status. Cancer J Sci Am 4: 230-236

Leitzel K, Teramoto Y, Konrad K, Chinchilli VM, Volas G, Grossberg H, Harvey H, Demers L, Lipton A (1995) Elevated serum c-erbB-2 antigen levels and decreased response to hormone therapy of breast cancer. J Clin Oncol 13: 1129-1135

Lippman ME, Allegra JC (1980) Quantitative estrogen receptor analyses: the response to endocrine and cytotoxic chemotherapy in human breast cancer and the disease-free interval. Cancer 46: 2829-2834

Lippman ME, Allegra JC, Thompson EB, Simon R, Barlock A, Green L, Huff KK, Do HM, Aitken SC, Warren R (1978) The relation between estrogen receptors and response rate to cytotoxic chemotherapy in metastatic breast cancer. $N$ Engl J Med 298: 1223 - 1228

Lo SS, Wang HC, Shyr YM, Lui WY (1994) Can the hormonal receptor status of primary breast cancer be altered by neoadjuvant chemotherapy? J Surg Oncol 57: 94-96

MacGrogan G, Rudolph P, Mascarel Id I, Mauriac L, Durand M, Avril A, Dilhuydy JM, Robert J, Mathoulin-Pelissier S, Picot V, Floquet A, Sierankowski G, Coindre JM (2003) DNA topoisomerase IIalpha expression and the response to primary chemotherapy in breast cancer. Br J Cancer 89: 666-671

Makris A, Powles TJ, Ashley SE, Chang J, Hickish T, Tidy VA, Nash AG, Ford HT (1998) A reduction in the requirements for mastectomy in a randomized trial of neoadjuvant chemoendocrine therapy in primary breast cancer. Ann Oncol 9: 1179-1184

Makris A, Powles TJ, Dowsett M, Osborne CK, Trott PA, Fernando IN, Ashley SE, Ormerod MG, Titley JC, Gregory RK, Allred DC (1997) Prediction of response to neoadjuvant chemoendocrine therapy in primary breast carcinomas. Clin Cancer Res 3: 593-600

Mauriac L, Durand M, Avril A, Dilhuydy JM (1991) Effects of primary chemotherapy in conservative treatment of breast cancer patients with operable tumors larger than $3 \mathrm{~cm}$. Results of a randomized trial in a single centre. Ann Oncol 2: 347-354
Meden H, Neues KP, Roben-Kampken S, Kuhn W (1995) A clinical, mammographic, sonographic and histologic evaluation of breast cancer. Int J Gynaecol Obstet 48: 193-199

Merkel DE, Winchester DJ, Goldschmidt RA, August CZ, Wruck DM, Rademaker AW (1993) DNA flow cytometry and pathologic grading as prognostic guides in axillary lymph node-negative breast cancer. Cancer 72: $1926-1932$

Muss HB, Thor AD, Berry DA, Kute T, Liu ET, Koerner F, Cirrincione CT, Budman DR, Wood WC, Barcos M, Henderson IC (1994) c-erbB-2 expression and response to adjuvant therapy in women with nodepositive early breast cancer. $N$ Engl J Med 330: $1260-1266$

Nicholson RI, McClelland RA, Finlay P, Eaton CL, Gullick WJ, Dixon AR, Robertson JF, Ellis IO, Blamey RW (1993) Relationship between EGF-R, c-erbB-2 protein expression and Ki67 immunostaining in breast cancer and hormone sensitivity. Eur J Cancer 29A: 1018-1023

Nishimura R, Nagao K, Miyayama H, Matsuda M, Baba K, Matsuoka Y, Yamashita H, Fukuda M (2002) An evaluation of predictive factors involved in clinical or pathological response to primary chemotherapy in advanced breast cancer. Breast Cancer 9: $145-152$

Ozmen V, Cabioglu N, Dolay K, Bilir A, Kecer M, Aydiner A, Muslumanoglu M, Igci A, Bozfakioglu Y, Dagoglu T (2001) Biological considerations in locally advanced breast cancer treated with anthracycline-based neoadjuvant chemotherapy: thymidine labelling index is an independent indicator of clinical outcome. Breast Cancer Res Treat 68: $147-157$

Paik S, Bryant J, Park C, Fisher B, Tan-Chiu E, Hyams D, Fisher ER, Lippman ME, Wickerham DL, Wolmark N (1998) erbB-2 and response to doxorubicin in patients with axillary lymph node-positive, hormone receptor-negative breast cancer. J Natl Cancer Inst 90: 1361 - 1370

Pain JA, Ebbs SR, Hern RP, Lowe S, Bradbeer JW (1992) Assessment of breast cancer size: a comparison of methods. Eur J Surg Oncol 18: $44-48$

Perou CM, Sorlie T, Eisen MB, van de Rijn M, Jeffrey SS, Rees CA, Pollack JR, Ross DT, Johnsen H, Akslen LA, Fluge O, Pergamenschikov A, Williams C, Zhu SX, Lonning PE, Borresen-Dale AL, Brown PO, Botstein D (2000) Molecular portraits of human breast tumours. Nature 406: $747-752$

Pisansky TM, Ingle JN, Schaid DJ, Hass AC, Krook JE, Donohue JH, Witzig TE, Wold LE (1993) Patterns of tumor relapse following mastectomy and adjuvant systemic therapy in patients with axillary lymph node-positive breast cancer. Impact of clinical, histopathologic, and flow cytometric factors. Cancer 72: $1247-1260$

Remvikos Y, Beuzeboc P, Zajdela A, Voillemot N, Magdelenat H, Pouillart P (1989) Correlation of pretreatment proliferative activity of breast cancer with the response to cytotoxic chemotherapy. J Natl Cancer Inst 81: $1383-1387$

Sataloff DM, Mason BA, Prestipino AJ, Seinige UL, Lieber CP, Baloch Z (1995) Pathologic response to induction chemotherapy in locally advanced carcinoma of the breast: a determinant of outcome. J Am Coll Surg 180: $297-306$

Schneider J, Lucas R, Sanchez J, Ruibal A, Tejerina A, Martin M (2000) Modulation of molecular marker expression by induction chemotherapy in locally advanced breast cancer: correlation with the response to therapy and the expression of MDR1 and LRP. Anticancer Res 20: $4373-4377$

Silvestrini R, Daidone MG, Valagussa P, Salvadori B, Rovini D, Bonadonna G (1987) Cell kinetics as a prognostic marker in locally advanced breast cancer. Cancer Treat Rep 71: 375-379

Slamon DJ, Clark GM, Wong SG, Levin WJ, Ullrich A, McGuire WL (1987) Human breast cancer: correlation of relapse and survival with amplification of the HER-2/neu oncogene. Science 235: 177-182

Smith IC, Welch AE, Hutcheon AW, Miller ID, Payne S, Chilcott F, Waikar S, Whitaker T, Ah-See AK, Eremin O, Heys SD, Gilbert FJ, Sharp PF (2000) Positron emission tomography using [(18)F]-fluorodeoxy-Dglucose to predict the pathologic response of breast cancer to primary chemotherapy. J Clin Oncol 18: 1676-1688

Tahan SR, Neuberg DS, Dieffenbach A, Yacoub L (1993) Prediction of early relapse and shortened survival in patients with breast cancer by proliferating cell nuclear antigen score. Cancer 71: $3552-3559$

Taucher S, Rudas M, Gnant M, Thomanek K, Dubsky P, Roka S, Bachleitner T, Kandioler D, Wenzel C, Steger G, Mittlbock M, Jakesz R (2003a) Sequential steroid hormone receptor measurements in primary breast cancer with and without intervening primary chemotherapy. Endocr Relat Cancer 10: 91 -98 
ER, PgR, HER-2, Ki-67 and anthracycline chemotherapy

RJ Burcombe et al

Taucher S, Rudas M, Mader RM, Gnant M, Sporn E, Dubsky P, Roka S, Bachleitner T, Fitzal F, Kandioler D, Wenzel C, Steger GG, Mittlbock M, Jakesz R (2003b) Influence of neoadjuvant therapy with epirubicin and docetaxel on the expression of HER2/neu in patients with breast cancer. Breast Cancer Res Treat 82: 207-213

Thor AD, Berry DA, Budman DR, Muss HB, Kute T, Henderson IC, Barcos M, Cirrincione C, Edgerton S, Allred C, Norton L, Liu ET (1998) erbB-2, p53, and efficacy of adjuvant therapy in lymph node-positive breast cancer. J Natl Cancer Inst 90: 1346-1360
Willsher PC, Pinder SE, Gee JM, Ellis IO, Chan SY, Nicholson RI, Blamey RW, Robertson JF (1998) C-erbB2 expression predicts response to preoperative chemotherapy for locally advanced breast cancer. Anticancer Res 18: 3695 - 3698

Yamauchi H, O'Neill A, Gelman R, Carney W, Tenney DY, Hosch S, Hayes DF (1997) Prediction of response to antiestrogen therapy in advanced breast cancer patients by pretreatment circulating levels of extracellular domain of the HER-2/c-neu protein. J Clin Oncol 15: $2518-2525$ 